\title{
Childhood cognitive ability: relationship to gestational diabetes mellitus in India
}

\author{
S. R. Veena • G. V. Krishnaveni • K. Srinivasan • \\ A. V. Kurpad • S. Muthayya • J. C. Hill • K. N. Kiran • \\ C. H. D. Fall
}

Received: 18 March 2010 / Accepted: 17 June 2010 /Published online: 8 July 2010

(C) Springer-Verlag 2010

\begin{abstract}
Aims/hypothesis Our aim was to test the hypothesis that gestational diabetes mellitus (GDM) in mothers is associated with poorer cognitive ability in their offspring in India. Methods During 1997 to 1998 maternal GDM status was assessed by OGTT at $30 \pm 2$ weeks of gestation. Between 2007 and 2008, at a mean age of 9.7 years, 515 children (32 offspring of GDM mothers [ODM]; 483 offspring of nonGDM mothers [controls]) from the Mysore Parthenon birth cohort underwent cognitive function assessment using tests from the Kaufman Assessment Battery for ChildrenSecond Edition and additional tests measuring learning, long-term storage/retrieval, short-term memory, reasoning, attention and concentration, and visuo-spatial and verbal abilities.

Results Compared with controls, ODM scored higher in tests for learning, long-term retrieval/storage $(p=0.008)$, reasoning $(p=0.02)$, verbal ability $(p=0.01)$, and attention and concentration $(p=0.003)$. In multiple regression, adjust-
\end{abstract}

Electronic supplementary material The online version of this article (doi:10.1007/s00125-010-1847-0) contains supplementary material, which is available to authorised users.

S. R. Veena $(\bowtie) \cdot$ G. V. Krishnaveni $\cdot$ K. N. Kiran

Epidemiology Research Unit, Holdsworth Memorial Hospital,

Mandi Mohalla, P.O. Box 38, Mysore 570021, India

e-mail: veenasr@gmail.com

K. Srinivasan · A. V. Kurpad $\cdot$ S. Muthayya

St John's Research Institute,

St John's National Academy of Health Sciences,

Bangalore, India

J. C. Hill • C. H. D. Fall

MRC Epidemiology Resource Centre,

Southampton General Hospital,

Southampton, UK ed for the child's age, sex, gestation, neonatal weight and head circumference, maternal age, parity and BMI, and the parent's socioeconomic status, education and rural/urban residence, this difference remained significant only for learning, long-term retrieval/storage $(\beta=0.4 \mathrm{SD}(95 \% \mathrm{CI}$ $0.01-0.75) ; p=0.04)$ and verbal ability $(\beta=0.5 \mathrm{SD}(95 \% \mathrm{CI}$ $0.09-0.83) ; p=0.02$ ), and not with other test scores.

Conclusions/interpretation In this population of healthy Indian children, there was no evidence of lower cognitive ability in ODM. In fact some cognitive scores were higher in ODM.

Keywords Children - Cognitive function - Gestational diabetes mellitus $\cdot$ India

$\begin{array}{ll}\text { Abbreviations } \\ \text { GDM } & \text { Gestational diabetes mellitus } \\ \text { ODM } & \begin{array}{l}\text { Offspring of mothers with gestational diabetes } \\ \text { mellitus }\end{array} \\ \text { SES } & \text { Socioeconomic status }\end{array}$

\section{Introduction}

The prevalence of gestational diabetes mellitus (GDM) is increasing in India and is estimated to be as high as $10-20 \%$ in urban populations [1]. Some studies have reported language impairment, inattention, motor delays and lower intelligence score among offspring of GDM mothers (ODM) [2, 3]. The Mysore Parthenon cohort was established to study the effects of GDM on offspring body composition and glucose/insulin metabolism [4], and enabled us to examine cognitive ability in children (aged 9-10 years) in relation to maternal GDM status. 


\section{Methods}

The cohort methodology has been reported in detail elsewhere [4]. Of 785 pregnant women recruited in 19971998 who completed an OGTT at $30 \pm 2$ weeks' gestation, 630 delivered live, normal babies at the Holdsworth Memorial Hospital, Mysore, India. GDM (defined by Carpenter-Coustan criteria [5]) was diagnosed in 49 $(6.9 \%)$ women. Following the OGTT, women diagnosed as having GDM were managed by their consultant obstetricians and therefore no information is available about the treatment and metabolic control of these women. The children had detailed anthropometric measurements at birth, and then each year until the age of 5 years and every 6 months thereafter. We extracted data from labour ward records concerning complications in pregnancy (pre-term delivery, pregnancy-induced hypertension, maternal infection), mode of delivery and neonatal Apgar score.

During 2007-2008, cognitive function was assessed among 515 available children ( $82 \%$ of the original cohort, aged 9-10 years: 32 ODM and 483 offspring of non-GDM mothers [controls]) using three core tests from Kaufman's Assessment Battery for Children-Second Edition [6] and additional tests $[7,8]$ measuring learning, longterm retrieval/storage (Atlantis), short-term memory (word order), reasoning (pattern reasoning), attention and concentration (Coding-Wechsler Intelligence Scale for ChildrenThird Edition), visuo-spatial (Kohs block-design test) and verbal abilities. Detailed descriptions of these tests are described in the Electronic supplementary material (ESM) Table 1 and also reported in our earlier publication [9].

We also collected data on: maternal age, parity, BMI, height and urban/rural residence in pregnancy; the child's sex, gestation, neonatal weight and head circumference, and current age, BMI and height; and the parent's educational level and socioeconomic status (SES) measured using the Standard of Living Index [10].

The hospital research ethics committee approved the study and informed consent was obtained from parents and children.

Statistical methods Variables with skewed distributions were either log-transformed (maternal BMI and visuospatial ability) or square-root transformed (pattern reasoning). Cognitive test scores (transformed and non-transformed) were $z$-standardised. Differences between ODM and controls were analysed using unpaired $t$ tests and chi-square tests. Multiple regression analysis, adjusting for potential covariates/confounders, was performed to examine offspring cognitive ability in relation to GDM status. Stata version 10 (Stata Corporation, College Station, TX, USA) was used for all analyses.

\section{Results}

As previously described [4] GDM women were older, shorter, had higher BMI in pregnancy, and better educational attainment than non-GDM women (Table 1). SES and the proportion living in an urban rather than rural setting were higher among the GDM group, although these differences were not statistically significant. ODM had higher birthweight, larger neonatal head circumference and higher current BMI than controls.

All the cognitive scores increased with increasing SES and parental educational level $(p<0.001$ for all; data not shown). Children of primiparous mothers performed better than children of multiparous mothers in tests of learning, longterm retrieval/storage $(p=0.004)$, short-term memory $(p=0.03)$, reasoning $(p=0.001)$ and verbal fluency $(p=0.001)$. The cognitive performance of urban children was better than rural children in tests of learning, long-term retrieval/ storage ( $p<0.001)$, short-term memory $(p=0.004)$, reasoning $(p=0.001)$ and visuo-spatial ability $(p=0.001)$. Reasoning and visuo-spatial ability scores increased with increasing maternal age $(p<0.001$ for both).

Mean cognitive scores were higher in ODM than controls, statistically significantly for long-term retrieval/ storage, reasoning, verbal ability and attention and concentration (Table 2). In multiple regression analysis the differences remained significant for learning, long-term retrieval/storage and verbal ability adjusted for the child's current age, sex, gestation, neonatal weight and head circumference, maternal age, parity and BMI, and the parents' SES, education and rural/urban residence. Although cognitive performance was better in girls than boys, there were no interactions between sex and GDM in relation to cognitive ability. Among controls, maternal 120 min glucose concentrations during OGTT, but not fasting glucose, were positively associated with the children's verbal ability $(p=0.02)$ and Atlantis score $(p=0.07)$.

\section{Discussion}

In this study of healthy Indian school-age children born in one maternity unit, cognitive scores were higher among ODM than controls. Both maternal GDM and higher cognitive performance in the children were associated with higher parental education and/or SES. However, the associations of GDM with better offspring learning, longterm storage/retrieval and verbal ability remained statistically significant after adjusting for these and all other potential confounding factors measured.

Strengths of the study were that we measured a battery of cognitive function tests specifically adapted for, and validated in, a South Indian population and also collected 
Table 1 Covariates/confounders according to maternal GDM status
Values are mean (SD) unless otherwise stated

${ }^{\mathrm{a}}$ Transformed variable; values are median (interquartile range)

${ }^{\mathrm{b}} p$ values are for the difference between ODM and controls derived using $t$ tests or chi-squared tests

\begin{tabular}{|c|c|c|c|}
\hline Covariates & ODM $(n=32)$ & Controls $(n=483)$ & $p$ value \\
\hline \multicolumn{4}{|l|}{ Maternal factors in pregnancy } \\
\hline Age (years) & $28.7(4.9)$ & $23.6(4.0)$ & $<0.0001$ \\
\hline Parity $2+, n(\%)$ & $6(18.8)$ & $82(17.0)$ & 0.8 \\
\hline Height $(\mathrm{cm})$ & $152.2(5.8)$ & $154.4(5.3)$ & 0.02 \\
\hline Body mass index $\left(\mathrm{kg} / \mathrm{m}^{2}\right)^{\mathrm{a}}$ & $27.1(25.0,29.1)$ & $23.1(20.9,25.9)$ & $<0.0001$ \\
\hline Fasting glucose concentration (mmol/l) & $5.8(1.7)$ & $4.5(0.4)$ & $<0.0001$ \\
\hline $120 \mathrm{~min}$ glucose concentration $(\mathrm{mmol} / \mathrm{l})$ & $9.8(4.0)$ & $5.8(1.1)$ & $<0.0001$ \\
\hline \multicolumn{4}{|l|}{ Infant factors at birth } \\
\hline Gestational age (weeks) & $39.3(1.2)$ & $39.3(1.6)$ & 0.9 \\
\hline Birthweight $(\mathrm{kg})$ & $3.270(0.459)$ & $2.854(0.441)$ & $<0.0001$ \\
\hline \multicolumn{4}{|l|}{ Birthweight (SD score) } \\
\hline Boys & $0.6(0.9)$ & $-0.002(1.01)$ & 0.08 \\
\hline Girls & $1.2(1.1)$ & $-0.07(1.0)$ & $<0.0001$ \\
\hline Head circumference $(\mathrm{cm})$ & $34.3(1.2)$ & $33.8(1.4)$ & 0.04 \\
\hline \multicolumn{4}{|l|}{ Head circumference (SD score) } \\
\hline Boys & $0.4(0.8)$ & $-0.01(1.0)$ & 0.2 \\
\hline Girls & $1.04(0.5)$ & $-0.04(1.0)$ & 0.03 \\
\hline \multicolumn{4}{|c|}{ Children's factors at the time of cognitive testing } \\
\hline Age (years) & $9.7(0.3)$ & $9.7(0.3)$ & 0.3 \\
\hline Height $(\mathrm{cm})$ & $131.3(6.2)$ & $130.7(5.7)$ & 0.6 \\
\hline \multicolumn{4}{|l|}{ Height (SD score) } \\
\hline Boys & $-0.70(1.07)$ & $-0.63(0.88)$ & 0.8 \\
\hline Girls & $-0.65(0.97)$ & $-0.85(0.95)$ & 0.3 \\
\hline Body mass index $\left(\mathrm{kg} / \mathrm{m}^{2}\right)$ & $15.9(1.8)$ & $14.5(1.8)$ & $<0.0001$ \\
\hline \multicolumn{4}{|l|}{ Body mass index (SD score) } \\
\hline Boys & $-0.75(1.13)$ & $-1.36(1.24)$ & 0.1 \\
\hline Girls & $-0.18(1.04)$ & $-1.26(1.22)$ & 0.0001 \\
\hline \multicolumn{4}{|l|}{ Parents' SES } \\
\hline Standard of living index (score) & $37.4(7.8)$ & $36.2(8.3)$ & 0.4 \\
\hline \multicolumn{4}{|l|}{ Maternal education, $n(\%)$} \\
\hline$<10$ completed years & $3(9.4)$ & $186(38.6)$ & \\
\hline 10 completed years & $10(31.2)$ & $149(30.9)$ & 0.001 \\
\hline$>10$ completed years & $19(59.4)$ & $147(30.5)$ & \\
\hline \multicolumn{4}{|l|}{ Paternal education, $n(\%)$} \\
\hline$<10$ completed years & $7(21.9)$ & $186(38.6)$ & \\
\hline 10 completed years & $20(62.5)$ & $183(38.0)$ & 0.02 \\
\hline$>10$ completed years & $5(15.6)$ & $113(23.4)$ & \\
\hline \multicolumn{4}{|l|}{ Residence } \\
\hline Rural, $n(\%)$ & $5(15.6)$ & $134(27.7)$ & 0.1 \\
\hline Urban, $n(\%)$ & $27(84.4)$ & $349(72.3)$ & \\
\hline
\end{tabular}

data on a range of potential covariates/confounders. Limitations in our study were a relatively small number of ODM, lack of data on the severity of GDM, treatment and maternal diet, and no information on parental intelligence and/or the home environment.

A recent case-control study reported a higher risk of language impairment in ODM compared with controls [2]. A recent review has reported no difference in cognitive ability among children born to mothers with or without
GDM, although compared with controls, ODM performed less well in fine and gross motor functions. Further, this review reported inverse associations of offspring intelligence scores, attention, language development, learning, memory span, and mental and psychomotor development with the severity of GDM assessed by glycosylated haemoglobin level and ketonuria, suggesting that the cognitive performance of offspring could be within normal limits in well-controlled GDM [3]. The reasons for our 


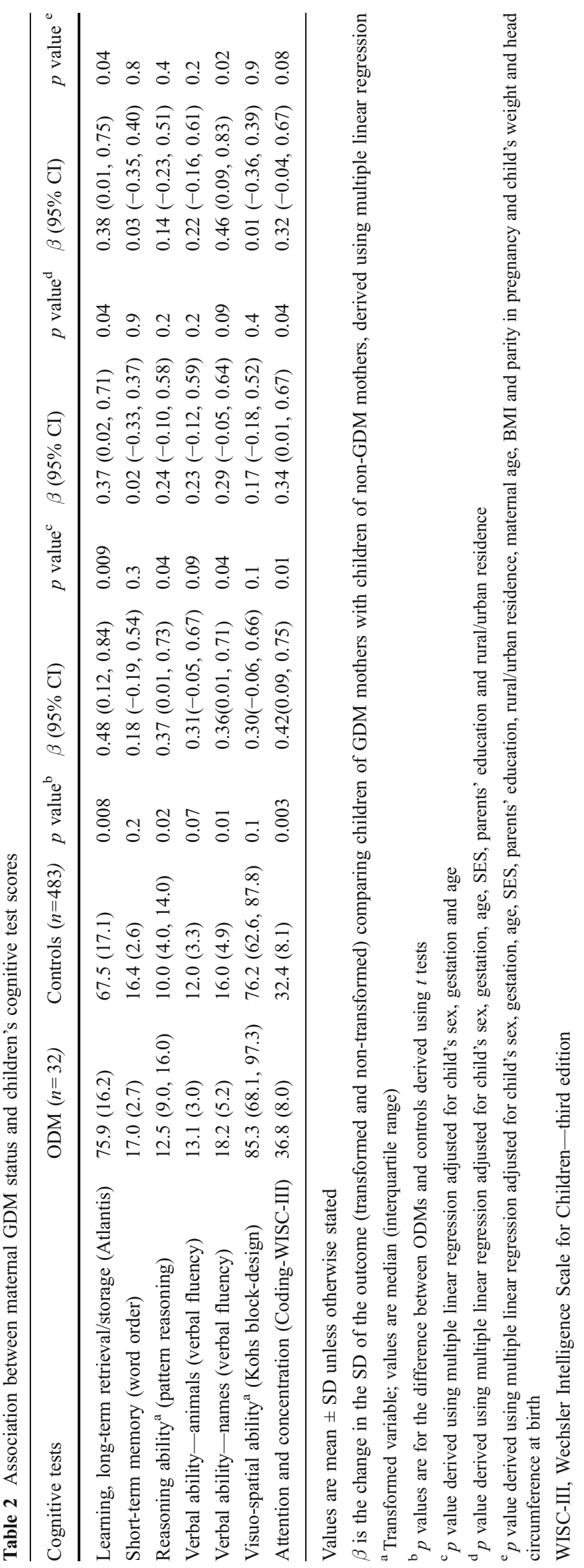


finding of higher cognitive function in ODM may be that there were no cases of severe or uncontrolled GDM in our study and/or that we were unable to completely adjust for the fact that in our population GDM was associated with higher maternal education, urban residence (and thus better schooling) and better childhood nutritional status (ODM had higher BMI). This effect may not be evident in studies in industrialised populations, where GDM tends to be associated with lower SES and lower maternal education [2]. Alternatively, the fetus of a mother with GDM is exposed to higher concentrations of glucose and fatty acids transferred across the placenta from the maternal circulation [11]. Theoretically these could enhance brain development. This is perhaps supported by our finding of positive associations of maternal 120 min glucose concentrations during OGTT with verbal ability and long-term retrieval/ storage among controls; unfortunately we do not have data on maternal circulating fatty acids.

In conclusion, in this population of healthy Indian children, there was no evidence of lower cognitive ability in ODM. In fact, some cognitive scores (two of the six cognitive parameters tested) were higher in ODM. This may be due to residual confounding. Although we adjusted for a number of confounding factors, no SES score can perfectly capture all the effects of SES, especially in India where there is a wide range of SES. Even in the SESmatched analysis there were significant differences in other important factors, such as maternal education, age and BMI, and child's birthweight and current BMI, between cases and controls. Alternatively the difference may be due to biological effect. The study suggests a need for further research to examine the relationship between GDM and cognitive ability in offspring in larger studies.

Acknowledgements We are grateful to the families for their participation. We thank all the staff of the Holdsworth Memorial Hospital Obstetric Department, I. Annamma, Lalitha, B. Balappa, G. Singh, Savitha, M.N. Swarnagowri, M.N. Jayakumar, A. Saroja, S. Geetha,
K.J. Chachyamma and S.J. Manohar (from Epidemiology Research Unit, HMH, Mysore), A.V. Ramthal and P.T. Pakkal (from St John's Research Institute, Bangalore), J. Pearce and P. Coakley (from MRC Epidemiology Resource Centre, Southampton) for their contributions, and Sneha-India for its support. The study was funded by the Parthenon Trust, Switzerland, the Wellcome Trust, UK, and the Medical Research Council, UK.

Duality of interest The authors declare that there is no duality of interest associated with this manuscript.

\section{References}

1. Seshiah V, Balaji V, Balaji MS, Paneerselvam A, Kapur A (2009) Pregnancy and diabetes scenario around the world. India. Int $\mathrm{J}$ Gynaecol Obstet 104:S35-S38

2. Dionne G, Boivin M, Séguin JR, Pérusse D, Tremblay RE (2008) Gestational diabetes hinders language development in offspring. Pediatrics 122:e1073-e1079

3. Ornoy A (2005) Growth and neurodevelopmental outcome of children born to mothers with pregestational and gestational diabetes. Pediatr Endocrinol Rev 3:104-113

4. Hill JC, Krishnaveni GV, Annamma I, Leary SD, Fall CH (2005) Glucose tolerance in pregnancy in South India: relationships to neonatal anthropometry. Acta Obstet Gynecol Scand 84:159-165

5. Carpenter MW, Coustan DR (1982) Criteria for screening for gestational diabetes. Am J Obstet Gynecol 159:768-773

6. Kaufman AS, Kaufman LN (2004) Kaufman assessment battery for children. Manual, 2nd edn. AGS Publishing, Circle Pines

7. Kohs SC (1923) Intelligence measurement: a psychological and statistical study based upon the block-design test. Macmillan, New York

8. Wechsler D (1991) Manual for the Wechsler Intelligence scale for children, 3rd edn. Psychological Corporation, San Antonio

9. Veena SR, Krishnaveni GV, Wills AK et al (2010) Association of birthweight and head circumference at birth to cognitive performance in 9-10 year old children in South India: prospective birth cohort study. Pediatr Res 67:424-429

10. International Institute for Population Sciences (IIPS) and Operations Research Centre (ORC) Macro (2001) National Family Health Survey (NFHS-2), India 1998-1999. IIPS, Maharashtra

11. Ortega-Senovilla H, Alvino G, Taricco E, Cetin I, Herrera E (2009) Gestational diabetes mellitus upsets the proportion of fatty acids in umbilical arterial but not venous plasma. Diabetes Care 32:120-122 